\title{
Climate change impacts on extreme events in the United States: an uncertainty analysis
}

\author{
Erwan Monier • Xiang Gao
}

Received: 31 January 2013 / Accepted: 19 December 2013 / Published online: 18 February 2014

(C) The Author(s) 2014. This article is published with open access at Springerlink.com

\begin{abstract}
In this study, we analyze changes in extreme temperature and precipitation over the US in a 60-member ensemble simulation of the 21st century with the Massachusetts Institute of Technology (MIT) Integrated Global System Model-Community Atmosphere Model (IGSM-CAM). Four values of climate sensitivity, three emissions scenarios and five initial conditions are considered. The results show a general intensification and an increase in the frequency of extreme hot temperatures and extreme precipitation events over most of the US. Extreme cold temperatures are projected to decrease in intensity and frequency, especially over the northern parts of the US. This study displays a wide range of future changes in extreme events in the US, even simulated by a single climate model. Results clearly show that the choice of policy is the largest source of uncertainty in the magnitude of the changes. The impact of the climate sensitivity is largest for the unconstrained emissions scenario and the implementation of a stabilization scenario drastically reduces the changes in extremes, even for the highest climate sensitivity considered. Finally, simulations with different initial conditions show conspicuously different patterns and magnitudes of changes in extreme events, underlining the role of natural variability in projections of changes in extreme events.
\end{abstract}

\section{Introduction}

Extreme weather and climate events, such as heat waves, droughts and severe precipitation events, have received increasing attention in recent years, due to the often-large

Electronic supplementary material The online version of this article (doi:10.1007/s10584-013-1048-1) contains supplementary material, which is available to authorized users.

This article is part of a Special Issue on "A Multi-Model Framework to Achieve Consistent Evaluation of Climate Change Impacts in the United States" edited by Jeremy Martinich, John Reilly, Stephanie Waldhoff, Marcus Sarofim, and James McFarland.

E. Monier $(\bowtie) \cdot$ X. Gao

Joint Program on the Science and Policy of Global Change, Massachusetts Institute of Technology, Cambridge, MA, USA 
impacts on society and ecosystems. Regional and global analyses of temperature extremes on land report statistically significant increases in the numbers of warm days and nights and decreases in the numbers of cold days and nights (Brown et al. 2008; Peterson et al. 2008; Meehl et al. 2009). In addition, there have been increases in the number of heavy precipitation events over the last half of the 20th century in more regions than there have been decreases (IPCC 2013). The overall most consistent trends toward increases in heavier precipitation events are found in North America (Peterson et al. 2008; DeGaetano 2009; Pryor et al. 2009; Gleason et al. 2008). Models project substantial increases in temperature extremes by the end of the 21 st century with the length, frequency, and/or intensity of warm spells and heat waves increasing over most land areas (Kharin et al. 2007; Sterl et al. 2008; Orlowsky and Seneviratne 2012). In addition, future climate simulations generally project increases in the greatest precipitation events over northwestern and northeastern US (Meehl et al. 2005). However, there are large uncertainties related to GCMs, RCMs and statistical downscaling methods, and by natural variability of the climate (Tebaldi et al. 2006; Kharin et al. 2007; Kyselỳ and Beranová 2009; Kenyon and Hegerl 2010; Orlowsky and Seneviratne 2012).

Extreme events can impact, directly or indirectly, all sectors of the economy. They can destroy large infrastructure and private properties, and lead to severe human losses. Various studies have examined the impacts of extreme events on infrastructure (Penning-Rowsell and Wilson 2006; Wright et al. 2012), air quality and human health (Leibensperger et al. 2008; Mahmud et al. 2012), terrestrial ecosystems (Parmesan et al. 2000; Xiao et al. 2009), agriculture and forestry (Rosenzweig et al. 2001; Maracchi et al. 2005), water demand (Strzepek et al. 2010), as well as energy demand and production (Smoyer-Tomic et al. 2003; Yergin 2006). For agriculture, single extreme weather events in the US can lead to economic damages that exceed $\$ 1$ billion (Rosenzweig et al. 2001). The widespread drought and excessive heat conditions in the Midwest and Great Plains in the summer of 2012 contributed to sharp decreases in yields and the crop insurance indemnities for 2012 losses totaled $\$ 16$ billion (Folger et al. 2013). Hurricanes Katrina and Rita shut down $27 \%$ of oil production in the US (Yergin 2006) and Hurricane Sandy inflicted approximately $\$ 65$ billion in economic losses across the US, the Caribbean, the Bahamas and Canada (Aon Benfield 2013). Extreme events can also cause substantial loss of life, like in 1998, when flooding and landslides due to Hurricane Mitch resulted in more than 10,000 deaths in Central America (Easterling et al. 2000) or like in 2003, when the European summer heat wave resulted in more than 70,000 deaths in 16 countries (Robine et al. 2008).

In this paper, we present projections of future changes in extreme temperature and precipitation using a consistent modeling framework with a focus on three key sources of uncertainty: (i) emissions projections; (ii) global climate system response; and (iii) natural variability. The simulations used in this analysis are part of a multi impact model project to achieve consistent evaluation of climate change impacts in the US (Waldhoff et al. 2013).

\section{Methodology}

\subsection{Model description}

For this study, we use an ensemble of climate simulations with the Massachusetts Institute of Technology (MIT) Integrated Global System Model-Community Atmosphere Model (IGSM-CAM) (Monier et al. 2013b). The IGSM is an integrated assessment model that couples an Earth System Model of Intermediate Complexity (EMIC), with a two-dimensional 
zonal-mean atmosphere, to a human activity model. The IGSM includes a representation of terrestrial water, energy, and ecosystem processes, global scale and urban chemistry including 33 chemical species, carbon and nitrogen cycle, thermodynamical sea ice, and ocean processes. In the IGSM-CAM framework, the IGSM (version 2.3) includes a threedimensional dynamical ocean component based on the MIT ocean general circulation model (Marshall et al. 1997a, b). The heat and freshwater fluxes are anomaly coupled in order to simulate a realistic ocean state. Observed wind stress from six-hourly National Centers for Environmental Prediction (NCEP) reanalysis (Kalnay et al. 1996) is used to more realistically capture surface wind forcing over the ocean. For any given model calendar year, a random calendar year of wind stress data is applied to the ocean in order to ensure that both short-term and interannual variability are represented in the ocean's surface forcing. Different random wind sampling can be applied to simulate different natural variability (Monier et al. 2013b). Finally, the human systems component of the IGSM is the MIT Emissions Predictions and Policy Analysis (EPPA) model (Paltsev et al. 2005), which provides projections of world economic development and emissions over 16 global regions along with analysis of proposed emissions control measures.

Since the IGSM includes a human activity model, it is possible to analyze uncertainties in emissions resulting from both uncertainty in model parameters and uncertainty in future climate policy decisions. Another major feature is the flexibility to vary key climate parameters controlling the climate response: climate sensitivity, strength of aerosol forcing and ocean heat uptake rate. Because the IGSM has a two-dimensional zonal-mean atmosphere, it cannot be directly used to simulate regional climate change. To simulate climate change over the US, the IGSM is linked to the National Center for Atmospheric Research (NCAR) Community Atmosphere Model (CAM) (Collins et al. 2006), with new modules developed and implemented in CAM to allow climate parameters to be changed to match those of the IGSM. In particular, the climate sensitivity of CAM is changed using a cloud radiative adjustment method (Sokolov and Monier 2012). In the IGSM-CAM framework, CAM is run at a horizontal resolution of $2^{\circ} \times 2.5^{\circ}$. More details on the IGSM-CAM framework can be found in (Monier et al. 2013b).

\subsection{Description of the simulations}

Uncertainty in future climate change is considered by running the IGSM-CAM with four values of climate sensitivity and three emissions scenarios, resulting in 12 core simulations. The three emissions scenarios considered are (i) a reference scenario with unconstrained emissions after 2012 (REF), with a total radiative forcing of $10.0 \mathrm{~W} / \mathrm{m}^{2}$ by 2100 ; (ii) a stabilization scenario (POL4.5), with a total radiative forcing of $4.5 \mathrm{~W} / \mathrm{m}^{2}$ by 2100 ; and (iii) a more stringent stabilization scenario (POL3.7), with a total radiative forcing of $3.7 \mathrm{~W} / \mathrm{m}^{2}$ by 2100 . More details on the emissions scenarios and economic implications, along with how they relate to the Representative Concentration Pathway (RCP) scenarios are given in Paltsev et al. (2013). The four values of climate sensitivity (CS) considered are 2.0, 3.0, 4.5 and $6.0^{\circ} \mathrm{C}$, which represent respectively the lower bound (CS2.0), best estimate (CS3.0) and upper bound (CS4.5) of climate sensitivity based on the Fourth Assessment Report of the Intergovernmental Panel on Climate Change (IPCC 2007), and a low probability/high risk climate sensitivity (CS6.0). The CS6.0 simulations are not treated the same as the others simulations, which represent the likely range, as they represent an outlier. Nonetheless, they provide a useful representation of a "worse-case scenario". The associated net aerosol forcing was chosen to ensure a good agreement with the observed climate change over the 20th century. The impact of the different values of climate sensitivity on the global climate 
response is also presented in Paltsev et al. (2013). For each set of climate sensitivities and emissions scenarios, a five-member ensemble is run with different initial conditions in the land, ocean and atmospheric components, as well as different random wind sampling, (simply referred to as initial conditions perturbation in the remainder of the article) to account for the uncertainty in natural variability in the climate system, resulting in a total of 60 simulations. Results are presented for the five-member ensemble means in order to better extract any long-term signal from the year-to-year variability and provide more robust results.

Monier et al. (2013a) provides an overview of the projected changes in mean temperature and precipitation over the US, along with an analysis of the contributions of various sources of uncertainty. Monier et al. (2013a) shows that the choice of the climate model has a large impact on the range and patterns of precipitation changes, much less so for changes in temperature. As a result, a limitation of this study is that we only use one atmospheric model. The consideration of other models would likely give a wider range of changes in extreme precipitation events and should be the focus of further research.

\subsection{Calculation of extreme events}

In this study we analyze the changes in extreme temperature and precipitation events over the US between present day (defined as the 1981-2010 period) and the 2086-2115 period (hereinafter referred to as 2100). There is a large number of methods used to define extreme events, whether based on an absolute threshold (e.g., maximum daily temperature exceeding $35^{\circ} \mathrm{C}$ ) or on the distribution of a variable (e.g., percentile method), or like the indices developed by the Expert Team on Climate Change Detection and Indices (ETCCDI, Klein Tank et al. 2009). In this study, we define three long-term extreme indices based a percentile method following Bell et al. (2004). To compute the extreme hot index (T99), the 99th percentile daily maximum temperature is calculated at each grid cell for each of the 30 years of the period considered (present day and future). These percentiles correspond essentially to the 4th hottest maximum temperature in a year. Then T99 is defined at each grid cell as the mean of the 30 99th percentile daily maximum temperature values. The extreme cold index (T01) and the extreme precipitation index (P99) are calculated in the same way but based on the 1st percentile daily minimum temperature values and on the 99th percentile daily precipitation. A similar extreme index method was used over the US in previous studies (Diffenbaugh et al. 2005; Walker and Diffenbaugh 2009), but considering the 5th and 95th percentiles, instead of the 1st and 99th percentiles, thus reducing the level of extreme events considered. In addition, they compute the extreme precipitation index using only rain days (defined as daily precipitation exceeding $1.0 \mathrm{~mm}$ ) for each year. As a result, future changes in the number of rain days (shown in Online Resource 1) would affect the changes in the extreme precipitation index, even if the magnitude and frequency of extreme events did not change. For this reason, the number of events selected for the calculation of P99 in this study is kept constant, regardless of the year or period considered.

We present results from the analysis of the change in intensity and frequency of T99, T01 and P99 from present day to 2100 . The change in frequency of T99 is defined as the change in number of days with maximum daily temperature above the present-day T99. For T01 and P99, the method to compute the change in frequency is slightly different. For T01, all simulations show a decrease in the number of days with minimum daily temperature below the present-day T01, caused by the ubiquitous warming. As a result, the decrease in the frequency of T01 is always between zero and 4 days (on average, there are 4 days with minimum daily temperature below the present-day T01 in the present-day period). Computed in this way, the change in frequency of T01 provides only limited information. For this 
reason, we calculate the decrease in the frequency of T01 as the change in the number of days with minimum daily temperature below the 2100 T99 (as a negative number). For P99, the change in frequency is computed like T99 when it shows an increase and like T01 when it shows a decrease.

The simulation of extreme events with the MIT IGSM-CAM framework is compared to the National Aeronautics and Space Administration (NASA) Modern Era RetrospectiveAnalysis for Research and Applications (MERRA) reanalysis (Rienecker et al. 2011), at $0.5^{\circ} \times 0.66^{\circ}$ resolution, and the NCEP/NCAR Reanalysis (Kalnay et al. 1996), at T62 gaussian grid (approximately $2^{\circ} \times 2^{\circ}$ resolution) .

\section{Results}

\subsection{Changes in extreme hot events}

Figure 1 presents maps of the present-day T99 for the MERRA and NCEP reanalyses and the IGSM-CAM. The IGSM-CAM simulation agrees reasonably well with the two

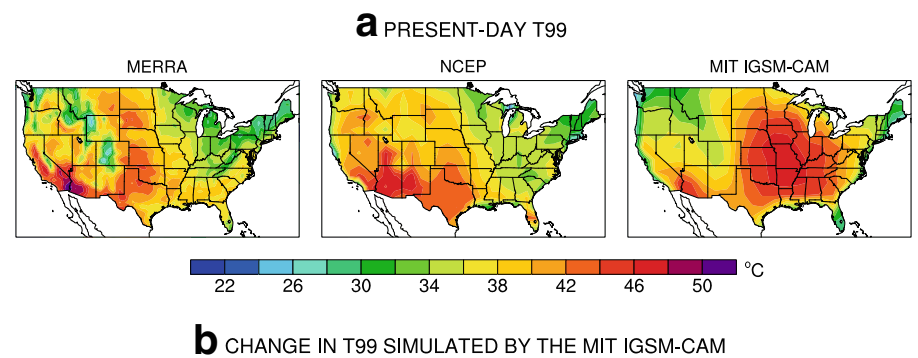

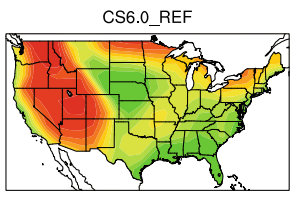

CS6.0_POL4.5

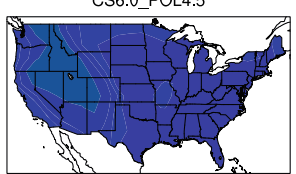

CS6.0_POL3.7

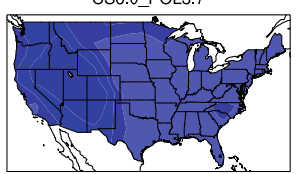

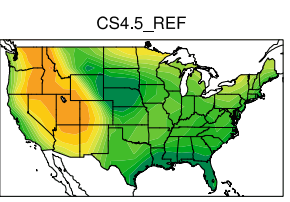

CS4.5_POL4.5

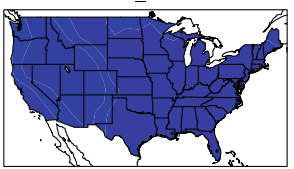

CS4.5_POL3.7

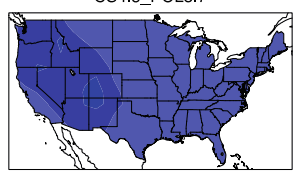

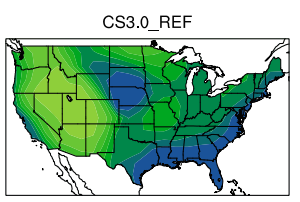

CS3.0_POL4.5

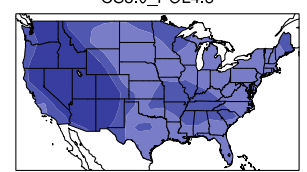

CS3.0_POL3.7

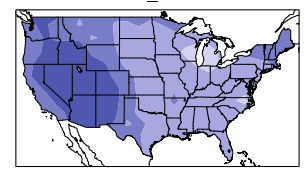

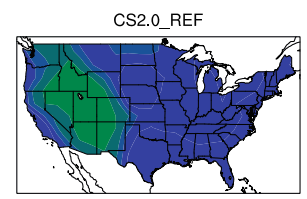

CS2.0 POL4.5
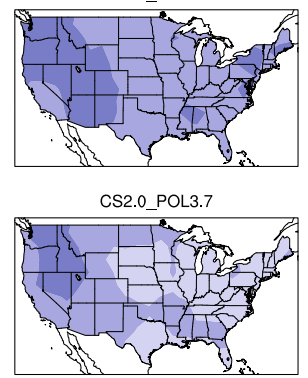

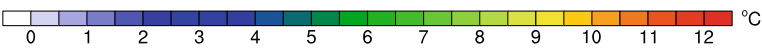

Fig. 1 a Present-day (1981-2010 period) annual 99th percentile of maximum daily temperature (T99) for the MERRA and NCEP reanalyses and the MIT IGSM-CAM and $\mathbf{b}$ change in T99 $\left({ }^{\circ} \mathrm{C}\right)$ simulated by the MIT IGSM-CAM for the 2085-2115 period relative to the 1981-2010 period. Changes are shown for each of the three emissions scenarios (REF, POL4.5 and POL3.7) and the four values of climate sensitivity $\left(\mathrm{CS}=2.0, \mathrm{CS}=3.0, \mathrm{CS}=4.5\right.$ and $\mathrm{CS}=6.0^{\circ} \mathrm{C}$ ) considered, averaged over five different initial conditions 
reanalyses over the Western US, but shows a warm bias over the Eastern US. The maximum in T99 shown in the two reanalyses over the Great Plains is simulated too far east and as a result, the T99 values are too high over the Great Lakes region and the Southeast. Such bias is not uncommon in simulations of extreme hot events over the US as shown in simulations using a high-resolution regional climate model (Walker and Diffenbaugh 2009). Figure 1 also shows maps of changes in T99 from present day to 2100 for the 12 core simulations, averaged over the five initial conditions. The general pattern of change in T99 exhibits a strong east-west dipole. The largest increases in T99 are found over the Western US, and to a lesser extent over the Great Lakes and New England. Under the reference scenario, the magnitude of increase in $\mathrm{T} 99$ ranges from $5^{\circ}$ to $10{ }^{\circ} \mathrm{C}$ (and up to $12{ }^{\circ} \mathrm{C}$ for CS6.0 simulation) over the Western Coast and from $2^{\circ}$ to $9{ }^{\circ} \mathrm{C}$ (and up to $11^{\circ} \mathrm{C}$ for the CS6.0 simulation) in the Eastern US. Such increases in T99 would likely have devastating impacts on both ecosystems and humans. To put this in perspective, during the European summer heat wave of 2003, Europe experienced summer surface air temperature anomalies (based on the JuneJuly-August daily averages) reaching up to $5.5{ }^{\circ} \mathrm{C}$ with respect to the $1961-1990$ mean (Garcia-Herrera et al. 2010). Instead of $5{ }^{\circ} \mathrm{C}$ anomaly from the mean, the present results suggest that, under the reference scenario, the present-day extreme temperatures are likely to increase by $5{ }^{\circ} \mathrm{C}$ over a large part of the US. However, under either policy scenario, the intensification of T99 would be drastically reduced, with increases of less than $3{ }^{\circ} \mathrm{C}$ over most of the US. Figure 2 shows maps of the change in T99 frequency. The simulations show a general increase in the number of extreme hot days. Similarly to the change in the intensity of T99, the largest changes take place over the Western US. Under the REF scenario, the maximum increases in the number of extreme hot days range from 50 to 100 . Over the rest of the US, there are between 10 and 40 more extreme hot days. Under either stabilization scenarios, the increase in the frequency of T99 is reduced to not more than 40 days per year.

CHANGE IN T99 FREQUENCY SIMULATED BY THE MIT IGSM-CAM

CS6.0 REF

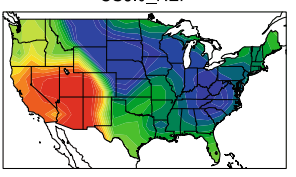

CS6.0_POL4.5

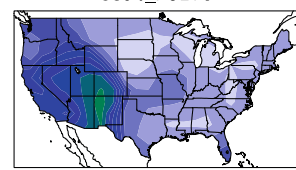

CS6.0 POL3.7

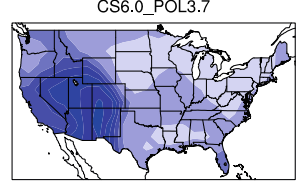

CS4.5_REF

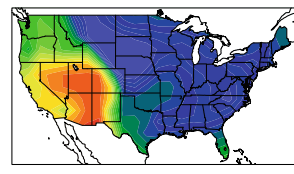

CS4.5_POL4.5

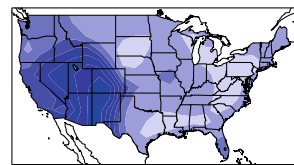

CS4.5_POL3.7

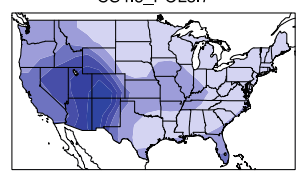

CS3.0 REF

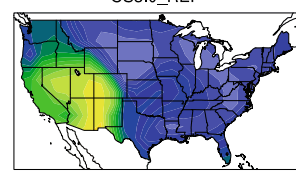

CS3.0_POL4.5

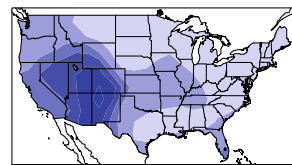

CS3.0_POL3.7

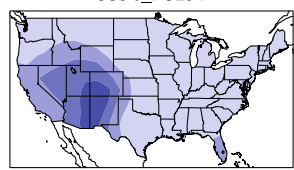

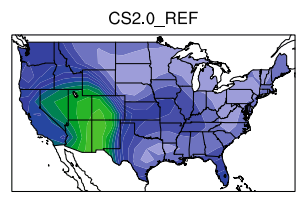

CS2.0 POL4.5

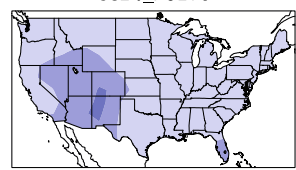

CS2.0 POL3.7

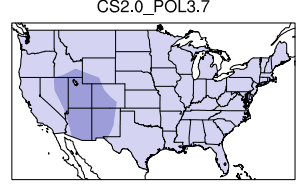

day/year

Fig. 2 Change in the frequency (day/year) of extreme hot days (T99) simulated by the MIT IGSM-CAM for the 2085-2115 period relative to the 1981-2010 period. Changes are shown for each of the three emissions scenarios (REF, POL4.5 and POL3.7) and the four values of climate sensitivity (CS $=2.0$, CS $=3.0$, $\mathrm{CS}=4.5$ and $\mathrm{CS}=6.0^{\circ} \mathrm{C}$ ) considered, averaged over five different initial conditions 


\subsection{Changes in extreme cold events}

Figure 3 shows maps of the present-day T01 for the two reanalyses and the IGSM-CAM. The IGSM-CAM realistically simulates the distribution and magnitude of T01, with a stronger agreement with the MERRA reanalysis over the Southern US. Nonetheless, the IGSM-CAM shows a warm bias over Wisconsin, Minnesota and North Dakota. Figure 3 also shows maps of changes in T01 from present day to 2100 for the 12 core simulations, averaged over the five initial conditions. The range of changes in T01 varies greatly among the different emissions scenarios and climate sensitivities. All simulations show increases in T01, with a general north-south dipole pattern. The largest increases take place in the Northern US and over the Rocky Mountains, and the least amount of change occurs over the Southern States. The impact of the climate sensitivity is strong among all emissions scenarios. Under the REF scenario, the maximum increases in T01 range from about $11^{\circ} \mathrm{C}$ to $22{ }^{\circ} \mathrm{C}$ (and above $22^{\circ} \mathrm{C}$ over most of the Northern US for the CS6.0 simulation). In comparison, the implementation of either policy scenario limits the increases in $\mathrm{T} 01$ to under $10^{\circ} \mathrm{C}$, regardless of the value of climate sensitivity. For the lowest climate sensitivity (CS2.0),

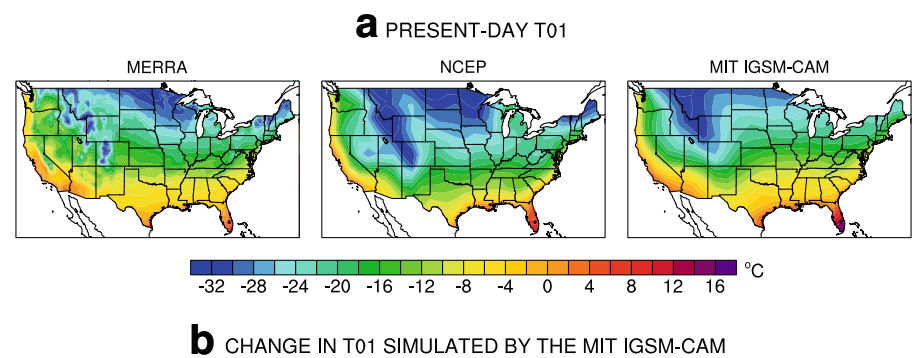

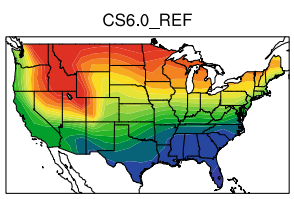

CS6.0_POL4.5

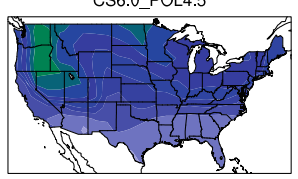

CS6.0_POL3.7

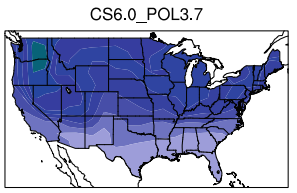

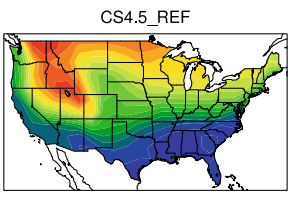

CS4.5_POL4.5

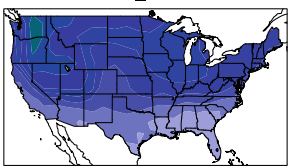

CS4.5_POL3.7

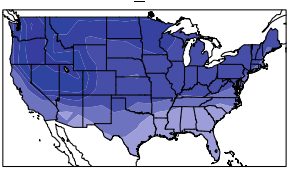

CS3.0_REF

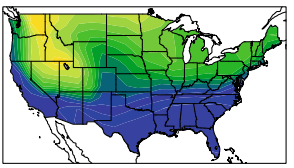

CS3.0_POL4.5

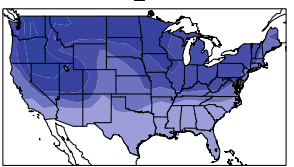

CS3.0_POL3.7

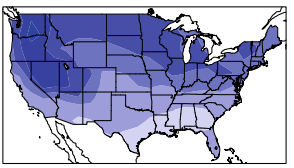

CS2.0_REF

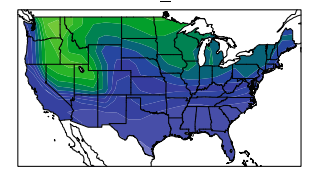

CS2.0_POL4.5

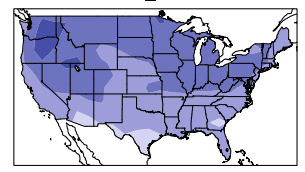

CS2.0_POL3.7

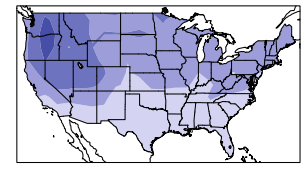

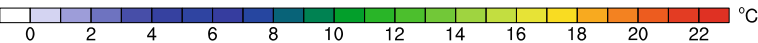

Fig. 3 a Present-day (1981-2010 period) annual 1st percentile of minimum daily temperature (T01) for the MERRA and NCEP reanalyses and the MIT IGSM-CAM and $\mathbf{b}$ change in T01 $\left({ }^{\circ} \mathrm{C}\right)$ simulated by the MIT IGSM-CAM for the 2085-2115 period relative to the 1981-2010 period. Changes are shown for each of the three emissions scenarios (REF, POL4.5 and POL3.7) and the four values of climate sensitivity (CS $=2.0$, $\mathrm{CS}=3.0, \mathrm{CS}=4.5$ and $\mathrm{CS}=6.0^{\circ} \mathrm{C}$ ) considered, averaged over five different initial conditions 
changes in T01 are less than $4{ }^{\circ} \mathrm{C}$ over the entire US. This underlines the risk of severe changes in extreme cold events under a reference scenario and the strong mitigating impact of the stabilization scenarios. Changes in T01 frequency are shown in Fig. 4. All simulations show a decrease in extreme cold days, with the largest changes over the Western and Northern US. Under the REF scenario, decreases vary from less than 20 days per year to 80 days per year (and to more than 100 days per year in the CS6.0 simulation). Under either stabilization scenarios, the decrease stays below 20 days per year.

\subsection{Changes in extreme precipitation events}

Figure 5 displays present-day P99 for the two reanalyses and the IGSM-CAM. The IGSMCAM simulates the distribution and magnitude of P99 well, with maximum values over the Northeast and Southeast and along the West Coast north of San Francisco. The differences between the IGSM-CAM and the MERRA reanalysis are generally as large as between the two reanalyses, thus within observational error. Figure 5 also shows maps of changes in P99 from present day to 2100 for the 12 core simulations, averaged over the five initial conditions. The IGSM-CAM simulations show a general increase in the intensity of extreme precipitation events, except over California. The increase in P99 is particularly strong over the Northeast and Southeast. The largest changes are coincident with the simulations with the largest warming (the higher the climate sensitivity and the higher the levels of greenhouse gases concentrations in the atmosphere). Therefore, the implementation of any stabilization policy will inevitably have great impacts. For example, the magnitudes of the increase in P99 in the CS6.0_POL4.5 scenario are similar to the CS2.0_REF scenario. Unlike changes in extreme temperature events, the patterns of precipitation change are less consistent between scenarios. This is particularly true for decreases in P99, which are smaller for CS6.0 than for the other climate sensitivities under the REF scenario. This is

CHANGE IN T01 FREQUENCY SIMULATED BY THE MIT IGSM-CAM

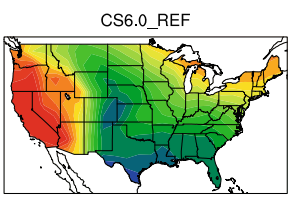

CS6.0_POL4.5

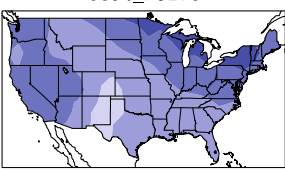

CS6.0_POL3.7

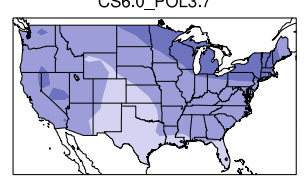

CS4.5_REF

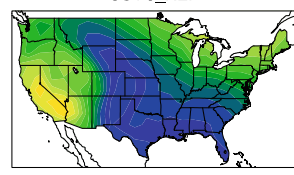

CS4.5_POL4.5

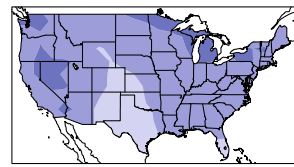

CS4.5_POL3.7

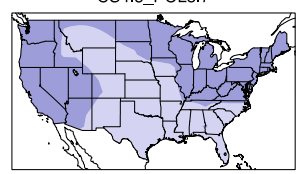

CS3.0_REF

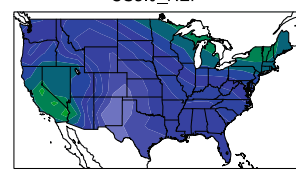

CS3.0_POL4.5

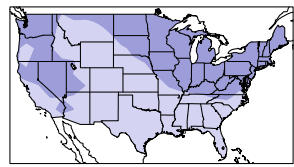

CS3.0_POL3.7

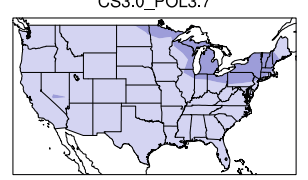

CS2.0_REF

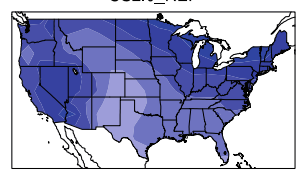

CS2.0_POL4.5

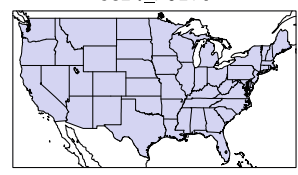

CS2.0_POL3.7

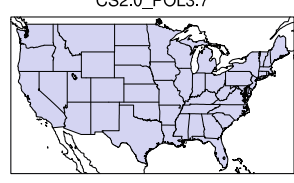

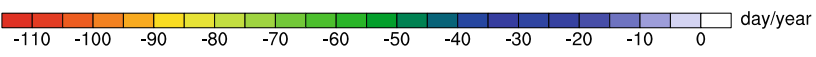

Fig. 4 Change in the frequency (day/year) of extreme cold days (T01) simulated by the MIT IGSM-CAM for the 2085-2115 period relative to the 1981-2010 period. Changes are shown for each of the three emissions scenarios (REF, POL4.5 and POL3.7) and the four values of climate sensitivity (CS $=2.0, \mathrm{CS}=3.0$, $\mathrm{CS}=4.5$ and $\mathrm{CS}=6.0^{\circ} \mathrm{C}$ ) considered, averaged over five different initial conditions 


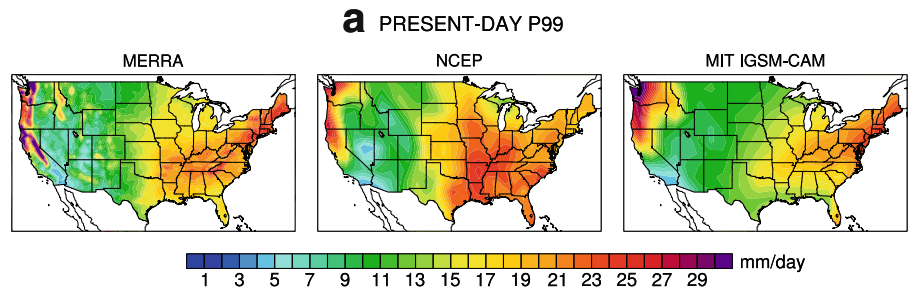

b CHANGE IN P9g SIMULATED BY THE MIT IGSM-CAM

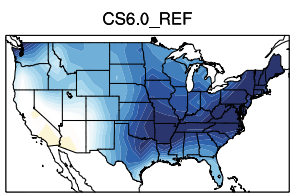

CS4.5_REF
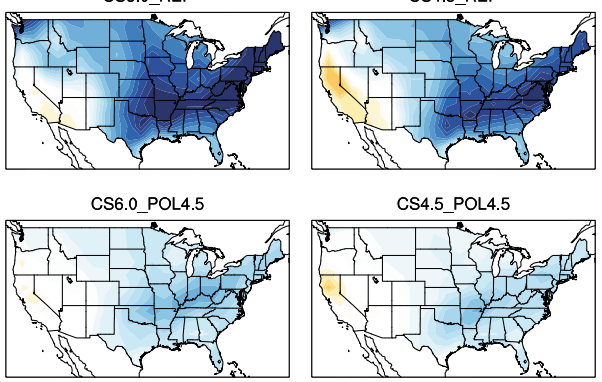

CS6.0_POL3.7

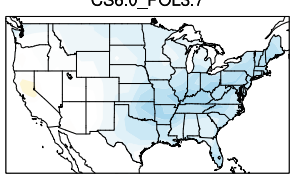

CS4.5_POL4.5

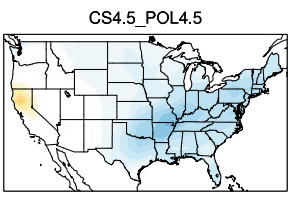

CS4.5_POL3.7

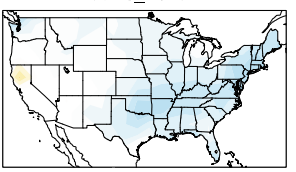

CS3.0_REF

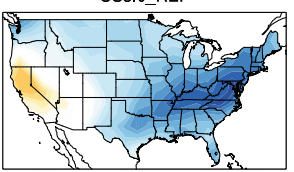

CS3.0_POL4.5

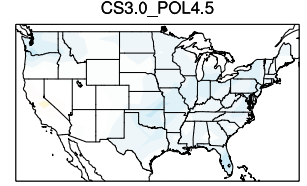

CS3.0_POL3.7

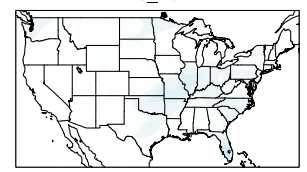

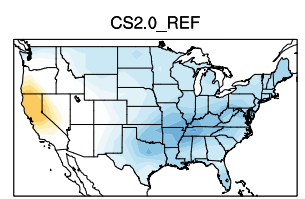

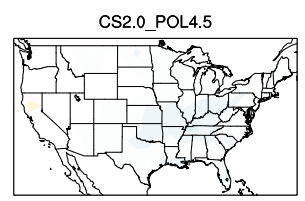

CS2.0_POL3.7

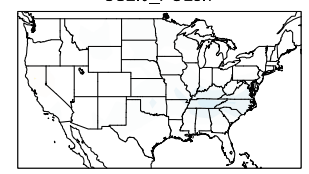

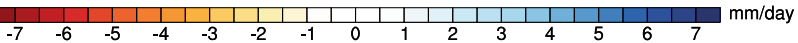

Fig. 5 a Present-day (1981-2010 period) annual 99th percentile of daily precipitation (P99) for the MERRA and NCEP reanalyses and the MIT IGSM-CAM and $\mathbf{b}$ change in P99 $(\mathrm{mm} / \mathrm{day})$ simulated by the MIT IGSM-CAM for the 2085-2115 period relative to the 1981-2010 period. Changes are shown for each of the three emissions scenarios (REF, POL4.5 and POL3.7) and the four values of climate sensitivity (CS $=2.0$, $\mathrm{CS}=3.0, \mathrm{CS}=4.5$ and $\mathrm{CS}=6.0^{\circ} \mathrm{C}$ ) considered, averaged over five different initial conditions

likely caused by the small size of the ensemble simulation with perturbations of initial conditions. Figure 6 shows the change in frequency of P99. While there is a general increase in the number of extreme precipitation events over most of the US, the patterns of change in the intensity and frequency of P99 are different. The largest increases in the number of extreme precipitation events takes place over the Great Plains. This means that a larger number of extreme events are projected, but not necessarily more intense. On the contrary, over the Northeast and Southeast, the intensity of extreme precipitation events is projected to increase more than the frequency. This underlines the heterogeneous response of changes in extreme precipitation events to climate change.

\subsection{Impact of the initial conditions}

Figure 7 shows maps of changes in T99, T01 and P99 under different initial conditions for the CS3.0_POL4.5 scenario. With different initial conditions, each simulation experiences conspicuously different patterns and magnitudes of change in extreme events. For example, some regions experience decreases in P99 in one of the simulations but increases in all the 
CHANGE IN P99 FREQUENCY SIMULATED BY THE MIT IGSM-CAM
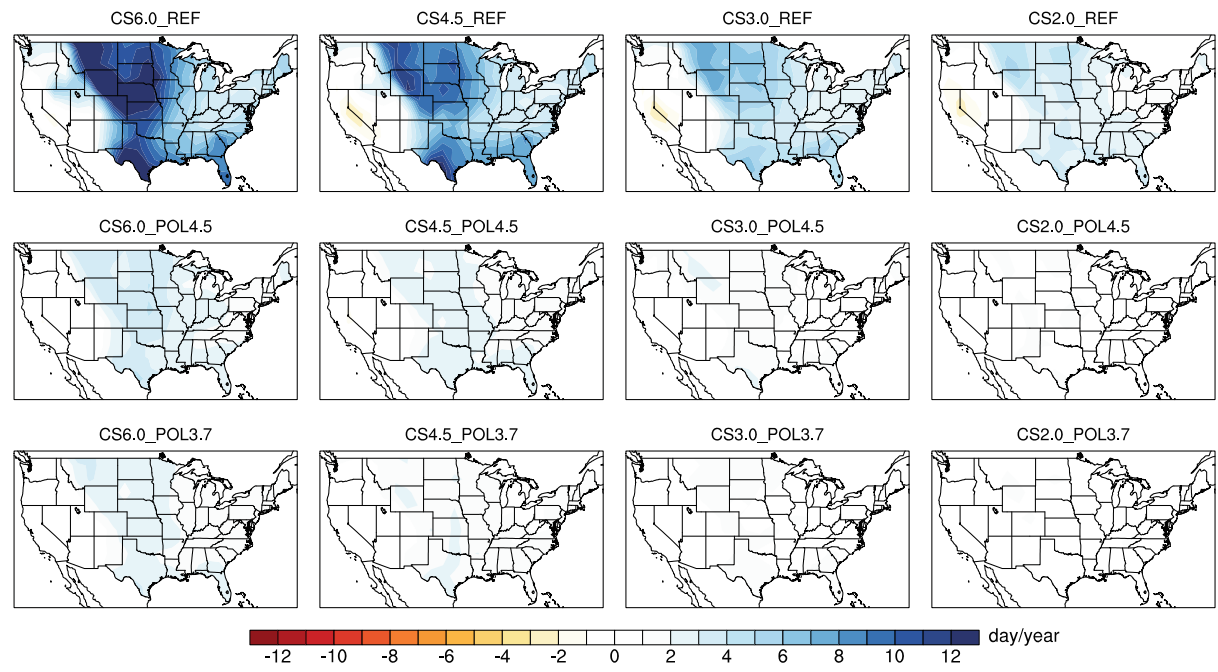

Fig. 6 Change in the frequency (day/year) of extreme precipitation events (P99) simulated by the MIT IGSM-CAM for the 2085-2115 period relative to the 1981-2010 period. Changes are shown for each of the three emissions scenarios (REF, POL4.5 and POL3.7) and the four values of climate sensitivity $(\mathrm{CS}=2.0$, $\mathrm{CS}=3.0, \mathrm{CS}=4.5$ and $\mathrm{CS}=6.0^{\circ} \mathrm{C}$ ) considered, averaged over five different initial conditions

a CHANGE IN T99 SIMULATED BY THE MIT IGSM-CAM
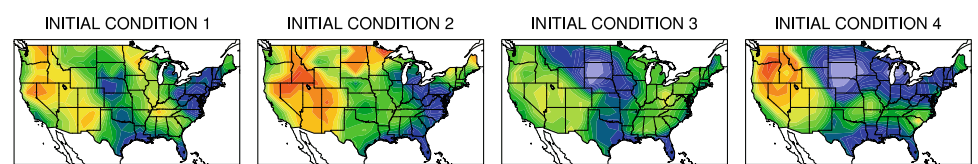

INITIAL CONDITION 5
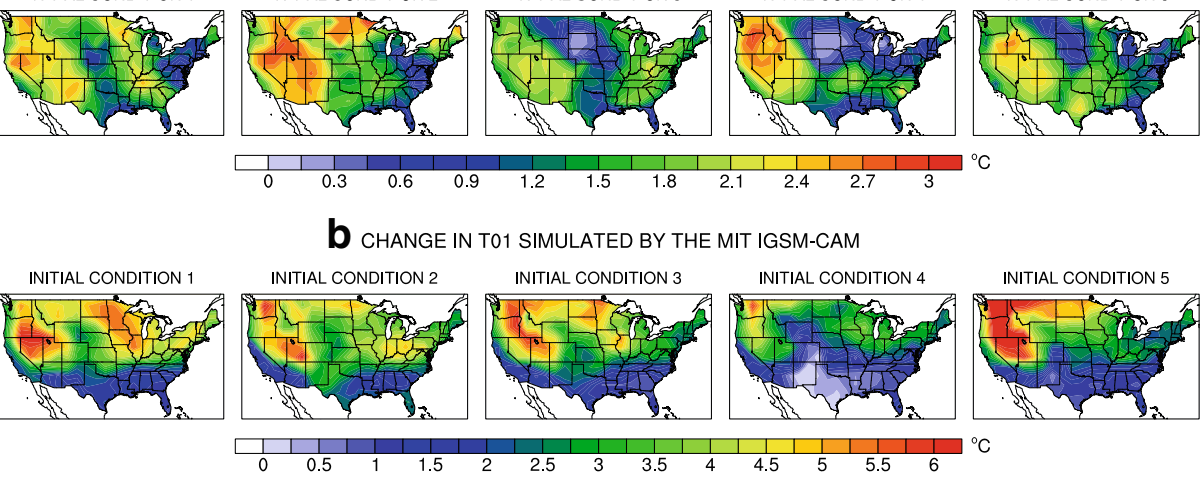

C CHANGE IN P9g SIMULATED BY THE MIT IGSM-CAM
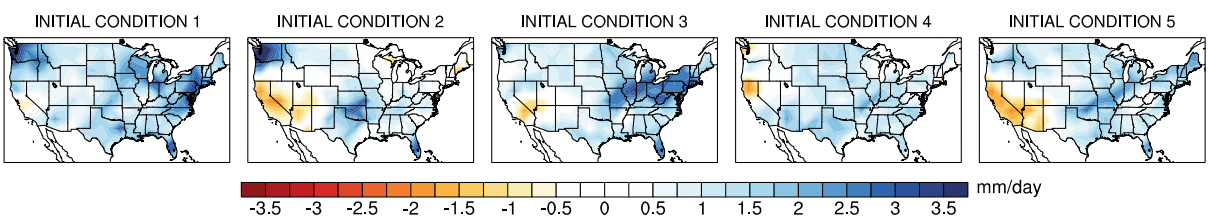

Fig. 7 Changes in a T99 $\left({ }^{\circ} \mathrm{C}\right)$, b T01 $\left({ }^{\circ} \mathrm{C}\right)$ and c P99 (mm/day) simulated by the MIT IGSM-CAM for the 2085-2115 period relative to the 1981-2010 period for each of the five different initial conditions under the CS3.0_POL4.5 scenario 
others, e.g., Maine (initial condition 2) and Washington (initial condition 4). Similarly, the extent of the decrease in P99 over California can vary from being very localized to Northern California (initial condition 4) to encompassing the entire state as well as most of Arizona (initial condition 5). This analysis reveals the important role of natural variability in future projections of changes in extreme events. It also demonstrates that one single model, under one single scenario, can simulate multiple equally plausible future climates with different changes in extreme events. For this reason, the consistency of the results for simulations with different initial conditions can be used to test the robustness of a particular pattern of change. In this case, this analysis suggests that the decrease in P99 over California is not very robust.

\section{Summary and conclusion}

In this study, we analyze changes in extreme events from 60 IGSM-CAM simulations of climate change used in a multi impact model project to achieve consistent evaluation of climate change impacts in the US. The IGSM-CAM simulations consider three sources of uncertainty in future climate projections: projected emissions, global climate response and natural variability.

The results show a general intensification and increase in the frequency of extreme hot temperatures and extreme precipitation events over most of the US. Extreme precipitation events are shown to decrease only over California, although this particular projection does not appear very robust. Extreme cold events become less frequent and less intense, especially over the northern parts of the US. These results are consistent among the various emissions scenarios and values of climate sensitivity, but with a wide range of magnitude. The choice of policy is the largest source of uncertainty in the magnitude of the changes in extreme events. The choice of climate sensitivity has the largest impact under the reference scenario. However, even under the lowest climate sensitivity considered, changes in extreme events are larger than under either stabilization scenarios, regardless of the climate sensitivity. Finally, simulations with different initial conditions show conspicuously different patterns and magnitudes of change in extreme events. This indicates the important role of natural variability in future projections of not only climate change (Monier et al. 2013a, c) but also changes in extreme events. It also underlines the importance of ensemble simulations with different initial conditions in order to better extract the anthropogenic signal from the noise. A summary of the analysis, area-averaged over the contiguous United States, can be found in Online Resource 2.

The changes in extreme temperature and precipitation events are likely to have important consequences. For example, more extreme hot events would lead to more wildfires and affect ecosystem carbon storage (Mills et al. 2013a). Decreases in extreme cold events can result in earlier springs, longer growing seasons, and higher crop productivity, which have been observed in the past few decades (Hicke et al. 2002). At the same time, it can result in decreases in the number of frost days and the expansion of the frost-free zone (see Online Resource 3), which would increase the survival of many insects and pests as well as the spread of crop diseases (Bale et al. 2002). Changes in extreme temperatures can also impact human morbidity and mortality (Luber and McGeehin 2008; O'Neill and Ebi 2009). There would likely be competing effects with a negative impact from increasing extreme hot temperatures and a positive impact from decreasing extreme cold temperatures (Mills et al. 2013b). Similarly, changes in extreme temperature would affect energy demand, with increasing extreme hot events leading to higher usage of air conditioning (Miller et al. 2008; 
McFarland et al. 2013). However, decreasing extreme cold temperatures would reduce the use of fuels for heating (Mansur et al. 2008). Finally, the increase in extreme precipitation may affect crop yields (Rosenzweig et al. 2002) or damage infrastructures (Wright et al. 2012). The complex interaction between the various changes in extreme events and the numerous impacts on economic sectors makes a comprehensive analysis of the climate change impacts difficult. This emphasizes the need for multi impact model projects to achieve consistent evaluation of climate change impacts in the US (Waldhoff et al. 2013).

Finally, it should be mentioned that this study suffers from limitations. First, only one atmospheric model is considered. Nonetheless, with one single model, we show that there is wide range of simulated future changes in extreme events over the US, when considering the uncertainty in emissions projections, climate response and natural variability. Thus, we wish to emphasize the need to consider multiple sources of uncertainty when simulating future changes in extreme events. Another limitation comes from the fact that extreme events are influenced by various modes of variability, such as El Niño-Southern Oscillation (ENSO) or the Northern Atlantic Oscillation (NAO). As a result, the projections of future changes in extreme events are likely to be dependent on the capabilities of the model to accurately simulate future changes in such modes of variability. Finally, the relatively low resolution of the IGSM-CAM might lead to biases in the realism of key atmospheric processes controlling extreme events. Walker and Diffenbaugh (2009) and Gao et al. (2012) show that higher resolution can provide more accurate simulations of extreme events. However, highresolution simulations are also too computationally demanding to run large ensembles that span a wide range of uncertainty.

Acknowledgments This work was partially funded by the US Environmental Protection Agency's Climate Change Division, under Cooperative Agreement \#XA-83600001 and by the National Science Foundation Macrosystems Biology Program Grant \#EF1137306. The Joint Program on the Science and Policy of Global Change is funded by a number of federal agencies and a consortium of 40 industrial and foundation sponsors. For a complete list of sponsors, see http://globalchange.mit.edu. This research used the Evergreen computing cluster at the Pacific Northwest National Laboratory. Evergreen is supported by the Office of Science of the US Department of Energy under Contract No. DE-AC05-76RL01830. NCEP Reanalysis data provided by the NOAA/OAR/ESRL PSD, Boulder, Colorado, USA, from their Web site at http://www.esrl.noaa.gov/psd/.

Open Access This article is distributed under the terms of the Creative Commons Attribution License which permits any use, distribution, and reproduction in any medium, provided the original author(s) and the source are credited.

\section{References}

Aon Benfield (2013) Annual global climate and catastrophe report: 2012. Tech. rep. http://thoughtleadership. aonbenfield.com/Documents/20130124_if_annual_global_climate_catastrophe_report.pdf

Bale J, Masters G, Hodkinson I, Awmack C, Bezemer T, Brown V, Butterfield J, Buse A, Coulson J, Farrar J, Good J, Harrington R, Hartley S, Jones T, Lindroth R, Press M, Symrnioudis I, Watt A, Whittaker J (2002) Herbivory in global climate change research: direct effects of rising temperature on insect herbivores. Glob Change Biol 8(1):1-16. doi:10.1046/j.1365-2486.2002.00451.x

Bell JL, Sloan LC, Snyder MA (2004) Regional changes in extreme climatic events: a future climate scenario. J Clim 17(1):81-87. doi:10.1175/1520-0442(2004)017<0081:RCIECE > 2.0.CO;2

Brown S, Caesar J, Ferro C (2008) Global changes in extreme daily temperature since 1950. J Geophys Res 113(D5):D05115. doi:10.1029/2006JD008091

Collins W, Rasch P, Boville B, Hack J, McCaa J, Williamson D, Briegleb B, Bitz C, Lin S, Zhang M (2006) The formulation and atmospheric simulation of the Community Atmosphere Model version 3 (CAM3). J Clim 19(11):2144-2161. doi:10.1175/JCLI3760.1 
DeGaetano AT (2009) Time-dependent changes in extreme-precipitation return-period amounts in the continental United States. J Appl Meteor Climatol 48(10):2086-2099. doi:10.1175/2009JAMC2179.1

Diffenbaugh NS, Pal JS, Trapp RJ, Giorgi F (2005) Fine-scale processes regulate the response of extreme events to global climate change. Proc Natl Acad Sci (USA) 102(44):15774-15778. doi:10.1073/pnas.0506042102

Easterling D, Evans J, Groisman P, Karl T, Kunkel K, Ambenje P (2000) Observed variability and trends in extreme climate events: a brief review. Bull Am Meteorol Soc 81(3):417-426. doi:10.1175/1520-0477 (2000)081 < 0417:OVATIE > 2.3.CO;2

Folger P, Cody BA, Carter NT (2013) Drought in the United States: causes and issues for congress. Tech. rep., Congressional Research Service, Washington DC

Gao Y, Fu J, Drake J, Liu Y, Lamarque J (2012) Projected changes of extreme weather events in the eastern United States based on a high resolution climate modeling system. Environ Res Lett 7(4):044025. doi:10.1088/1748-9326/7/4/044025

Garcia-Herrera R, Diaz J, Trigo RM, Luterbacher J, Fischer EM (2010) A review of the European summer heat wave of 2003. Crit Rev Environ Sci Technol 40(4):267-306. doi:10.1080/10643380802238137

Gleason KL, Lawrimore JH, Levinson DH, Karl TR, Karoly DJ (2008) A revised US climate extremes index. J Clim 21(10):2124-2137. doi:10.1175/2007JCLI1883.1

Hicke J, Asner G, Randerson J, Tucker C, Los S, Birdsey R, Jenkins J, Field C (2002) Trends in North American net primary productivity derived from satellite observations, 1982-1998. Glob Biogeochem Cycles 16(2):1018. doi:10.1029/2001GB001550

IPCC (2007) Climate change 2007: synthesis report. Contribution of working groups I, II and III to the fourth assessment report of the intergovernmental panel on climate change. Cambridge University Press, Cambridge, p 104

IPCC (2013) Climate change 2013: the physical science basis. Contribution of working group I to the fifth assessment report of the intergovernmental panel on climate change. Cambridge University Press, Cambridge, in press

Kalnay E, Kanamitsu M, Kistler R, Collins W, Deaven D, Gandin L, Iredell M, Saha S, White G, Woollen J, Zhu Y, Leetmaa A, Reynolds R, Chelliah M, Ebisuzaki W, Higgins W, Janowiak J, Mo KC, Ropelewski C, Wang J, Jenne R, Joseph D (1996) The NCEP/NCAR 40-year reanalysis project. Bull Am Meteorol Soc 77(3):437-471. doi:10.1175/1520-0477(1996)077<0437:TNYRP>2.0.CO;2

Kenyon J, Hegerl GC (2010) Influence of modes of climate variability on global precipitation extremes. J Clim 23(23):6248-6262. doi:10.1175/2010JCLI3617.1

Kharin VV, Zwiers FW, Zhang X, Hegerl GC (2007) Changes in temperature and precipitation extremes in the IPCC ensemble of global coupled model simulations. J Clim 20(8):1419-1444

Klein Tank AMG, Zwiers FW, Zhang X (2009) Guidelines on analysis of extremes in a changing climate in support of informed decisions for adaptation. Climate data and monitoring, WCDMP-No. 72, WMO-TD No. 1500 , p 56

Kyselỳ J, Beranová R (2009) Climate-change effects on extreme precipitation in central Europe: uncertainties of scenarios based on regional climate models. Theor Appl Climatol 95(3-4):361-374. doi:10.1007/s00704-008-0014-8

Leibensperger E, Mickley L, Jacob D (2008) Sensitivity of US air quality to mid-latitude cyclone frequency and implications of 1980-2006 climate change. Atmos Chem Phys 8(23):7075-7086. doi:10.5194/acp-8-7075-2008

Luber G, McGeehin M (2008) Climate change and extreme heat events. Am J Prev Med 35(5):429-435. doi:10.1016/j.amepre.2008.08.021

Mahmud A, Hixson M, Kleeman M (2012) Quantifying population exposure to airborne particulate matter during extreme events in California due to climate change. Atmos Chem Phys 12:7453-7463. doi:10.5194/acp-12-7453-2012

Mansur ET, Mendelsohn R, Morrison W (2008) Climate change adaptation: a study of fuel choice and consumption in the US energy sector. J Environ Econ Manage 55(2):175-193. doi:10.1016/j.jeem.2007.10.001

Maracchi G, Sirotenko O, Bindi M (2005) Impacts of present and future climate variability on agriculture and forestry in the temperate regions: Europe. Clim Change 70(1-2):117-135. doi:10.1007/s10584-005-5939-7

Marshall J, Adcroft A, Hill C, Perelman L, Heisey C (1997a) A finite-volume, incompressible navier stokes model for studies of the ocean on parallel computers. J Geophys Res 102(C3):5753-5766. doi:10.1029/96JC02775

Marshall J, Hill C, Perelman L, Adcroft A (1997b) Hydrostatic, quasi-hydrostatic, and nonhydrostatic ocean modeling. J Geophys Res 102(C3):5733-5752. doi:10.1029/96JC02776 
McFarland J, Zhou Y, Clarke L, Schultz P, Sullivan P, Colman J, Patel P, Eom J, Kim S, Kyle G, Jaglom W, Venkatesh B, Haydel J, Miller R, Creason J, Perkins B (2013) Modeling climate change impacts on energy supply and demand in the United States. Clim Chang, submitted this issue

Meehl G, Arblaster J, Tebaldi C (2005) Understanding future patterns of increased precipitation intensity in climate model simulations. Geophys Res Lett 32(18):L18719. doi:10.1029/2005GL023680

Meehl GA, Tebaldi C, Walton G, Easterling D, McDaniel L (2009) Relative increase of record high maximum temperatures compared to record low minimum temperatures in the US. Geophys Res Lett 36(L23701). doi:10.1029/2009GL040736

Miller NL, Hayhoe K, Jin J, Auffhammer M (2008) Climate, extreme heat, and electricity demand in California. J Appl Meteor Climatol 47(6):1834-1844. doi:10.1175/2007JAMC1480.1

Mills D, Jones R, Carney K, St Juliana A, Ready R, Crimmins A, Martinich J, Shouse K, DeAngelo B, Monier E (2013a) Quantifying and monetizing potential climate change policy impacts on terrestrial ecosystem carbon storage and wildfires in the United States. Clim Chang, submitted this issue

Mills D, Schwartz J, Lee M, Sarofim M, Jones R, Lawson M, Deck L (2013b) Climate change impacts on extreme temperature mortality in select metropolitan areas of the United States. Clim Chang, submitted this issue

Monier E, Gao X, Scott J, Sokolov A, Schlosser A (2013a) A framework for modeling uncertainty in regional climate change. Clim Chang, submitted this issue

Monier E, Scott JR, Sokolov AP, Forest CE, Schlosser CA (2013b) An integrated assessment modeling framework for uncertainty studies in global and regional climate change: the MIT IGSM-CAM (version 1.0). Geosci Model Dev 6:2063-2085. doi:10.5194/gmd-6-2063-2013

Monier E, Sokolov A, Schlosser A, Scott J, Gao X (2013c) Probabilistic projections of 21st century climate change over Northern Eurasia. Environ Res Lett 8:045008. doi:10.1088/1748-9326/8/4/045008

O'Neill MS, Ebi KL (2009) Temperature extremes and health: impacts of climate variability and change in the united states. J Occup Environ Med 51(1):13-25. doi:10.1097/JOM.0b013e318173e122

Orlowsky B, Seneviratne SI (2012) Global changes in extreme events: regional and seasonal dimension. Clim Chang 110(3-4):669-696. doi:10.1007/s10584-011-0122-9

Paltsev S, Reilly JM, Jacoby HD, Eckaus RS, McFarland J, Sarofim M, Asadoorian M, Babiker M (2005) The MIT Emissions Prediction and Policy Analysis (EPPA) model: version 4. Report 125, MIT Joint Program on the Science and Policy of Global Change. http://globalchange.mit.edu/files/document/MITJPSPGC Rpt125.pdf

Paltsev S, Monier E, Scott JR, Sokolov AP, Reilly JM (2013) Integrated economic and climate projections for impact assessment. Clim Chang, in press. doi:10.1007/s10584-013-0892-3

Parmesan C, Root T, Willig M (2000) Impacts of extreme weather and climate on terrestrial biota. Bull Am Meteorol Soc 81(3):443-450. doi:10.1175/1520-0477(2000)081<0443:IOEWAC>2.3.CO;2

Penning-Rowsell E, Wilson T (2006) Gauging the impact of natural hazards: the pattern and cost of emergency response during flood events. Trans Inst Br Geogr 31(2):99-115. doi:10.1111/j.1475-5661. 2006.00200.x

Peterson TC, Zhang X, Brunet-India M, Vázquez-Aguirre JL (2008) Changes in North American extremes derived from daily weather data. J Geophys Res 113(D7):D07113. doi:10.1029/2007JD009453

Pryor S, Howe J, Kunkel K (2009) How spatially coherent and statistically robust are temporal changes in extreme precipitation in the contiguous USA? Int J Climatol 29(1):31-45. doi:10.1002/joc.1696

Rienecker MM, Suarez MJ, Gelaro R, Todling R, Bacmeister J, Liu E, Bosilovich MG, Schubert SD, Takacs L, Kim GK, Bloom S, Chen J, Collins D, Conaty A, Da Silva A, Gu W, Joiner J, Koster RD, Lucchesi R, Molod A, Owens T, Pawson S, Pegion P, Redder CR, Reichle R, Robertson FR, Ruddick AG, Sienkiewicz M, Woollen J (2011) MERRA: NASA's Modern-Era Retrospective Analysis for Research and Applications. J Clim 24(14):3624-3648. doi:10.1175/JCLI-D-11-00015.1

Robine JM, Cheung SLK, Le Roy S, Van Oyen H, Griffiths C, Michel JP, Herrmann FR (2008) Death toll exceeded 70,000 in Europe during the summer of 2003. C R Biol 331(2):171-U5. doi:10.1016/j.crvi.2007.12.001

Rosenzweig C, Iglesias A, Yang X, Epstein P, Chivian E (2001) Climate change and extreme weather events; implications for food production, plant diseases, and pests. Glob Change Hum Health 2(2):90-104. doi:10.1023/A:1015086831467

Rosenzweig C, Tubiello FN, Goldberg R, Mills E, Bloomfield J (2002) Increased crop damage in the US from excess precipitation under climate change. Glob Environ Change 12(3):197-202. doi:10.1016/S0959-3780(02)00008-0

Smoyer-Tomic K, Kuhn R, Hudson A (2003) Heat wave hazards: an overview of heat wave impacts in Canada. Nat Hazards 28(2):465-486. doi:10.1023/A:1022946528157

Sokolov A, Monier E (2012) Changing the climate sensitivity of an atmospheric general circulation model through cloud radiative adjustment. J Clim 25(19):6567-6584. doi:10.1175/JCLI-D-11-00590.1 
Sterl A, Severijns C, Dijkstra H, Hazeleger W, van Oldenborgh GJ, van den Broeke M, Burgers G, van den Hurk B, van Leeuwen PJ, van Velthoven P (2008) When can we expect extremely high surface temperatures? Geophys Res Lett 35(14):L14703. doi:10.1029/2008GL034071

Strzepek K, Yohe G, Neumann J, Boehlert B (2010) Characterizing changes in drought risk for the United States from climate change. Environ Res Lett 5(4):044012. doi:10.1088/1748-9326/5/4/044012

Tebaldi C, Hayhoe K, Arblaster JM, Meehl GA (2006) Going to the extremes: an intercomparison of model-simulated historical and future changes in extreme events. Clim Chang 79(3-4):185-211. doi:10.1007/s10584-006-9051-4

Waldhoff S, Martinich J, Sarofim M, DeAngelo B, McFarland J, Jantarasami L, Shouse K, Crimmins A, Li J (2013) Overview of the special issue: a multi-model framework to achieve consistent evaluation of climate change impacts in the United States, under review

Walker M, Diffenbaugh N (2009) Evaluation of high-resolution simulations of daily-scale temperature and precipitation over the United States. Clim Dyn 33(7):1131-1147. doi:10.1007/s00382-009-0603-y

Wright L, Chinowsky P, Strzepek K, Jones R, Streeter R, Smith J, Mayotte J, Powell A, Jantarasami L, Perkins W (2012) Estimated effects of climate change on flood vulnerability of U.S. bridges. Mitig Adapt Strat Glob Change 17(8):939-955. doi:10.1007/s11027-011-9354-2

Xiao J, Zhuang Q, Liang E, Shao X, McGuire A, Moody A, Kicklighter D, Melillo J (2009) TwentiethCentury droughts and their impacts on terrestrial carbon cycling in China. Earth Interact 13(10):1-31. doi:10.1175/2009EI275.1

Yergin D (2006) Ensuring energy security. Foreign Aff 85(2):69-82. doi:10.2307/20031912 